\title{
Retraction
}

\section{Retraction: Powrozek and Miller, Ethanol Affects Transforming Growth Factor $\beta 1$-Initiated Signals: Cross-Talking Pathways in the Developing Rat Cerebral Wall}

The editors of The Journal of Neuroscience are retracting the article by Teresa A. Powrozek and Michael W. Miller, "Ethanol Affects Transforming Growth Factor $\beta 1$-Initiated Signals: Cross-Talking Pathways in the Developing Rat Cerebral Wall," which appeared on pages 9521-9533 of the July 29, 2009 issue. This decision was made after considering the findings of an investigation by the Society for Neuroscience, correspondence with SUNY Upstate Medical University, and the Office of Research Integrity Case Report on Michael W. Miller.

DOI:10.1523/JNEUROSCI.1177-13.2013 